Review

\title{
Association between BRCA1 P871L polymorphism and cancer risk: evidence from a meta-analysis
}

\author{
Limin Miao ${ }^{1, *}$, Yang Yu${ }^{1, *}$, Yefeng $\mathrm{Ji}^{1}$, Bo Zhang ${ }^{1}$, Zhiyao Yuan ${ }^{1}$, Yifei Du ${ }^{1}$, Longbiao \\ Zhu ${ }^{1}$, Ruixia Wang ${ }^{1}$, Ning Chen ${ }^{1,2}$ and Hua Yuan ${ }^{1,2}$ \\ 1 Jiangsu Key Laboratory of Oral Diseases, Nanjing Medical University, Nanjing, China \\ ${ }^{2}$ Department of Oral and Maxillofacial Surgery, Affiliated Hospital of Stomatology, Nanjing Medical University, Nanjing, China \\ * These authors have contributed equally to this work
}

Correspondence to: Hua Yuan, email: yuanhua@njmu.edu.cn

Keywords: BRCA 1, polymorphism, cancer risk, meta-analysis

Received: November 09, $2016 \quad$ Accepted: February 13,2017 Published: February 25, 2017

Copyright: Miao et al. This is an open-access article distributed under the terms of the Creative Commons Attribution License (CC-BY), which permits unrestricted use, distribution, and reproduction in any medium, provided the original author and source are credited.

\section{ABSTRACT}

Breast cancer 1 (BRCA1) gene makes great contributions to the repair of DNA. The association between BRCA1 P871L polymorphism and cancer risk has been investigated in a growing number of studies, but the conclusions are not conclusive. To obtain a comprehensive conclusion, we performed a meta-analysis of 24 studies with 13762 cases and 22388 controls. The pooled results indicated that BRCA1 gene P871L variant decreased risk of overall cancer (homozygous model: odds ratio (OR) $=$ $0.89,95 \%$ confidence interval $(\mathrm{CI})=0.79-1.00$; recessive model: $\mathrm{OR}=0.89,95 \% \mathrm{CI}$ $=0.80-0.99$ ). The stratified analysis observed decreased risk associated with BRCA1 P871L in subgroups among Asians and high score studies, but not Caucasians or low score studies. In conclusion, despite several limitations, this meta-analysis suggested that BRCA1 P871L genetic variation may be associated with decreased susceptibility to cancer.

\section{INTRODUCTION}

Cancer is one of serious diseases severely endangering the human health and lives. In 2012, the world had 14.1 million new cases of cancer and 8.2 million patients died from cancer [1]. The balance between DNA damage and repair has long been recognized to be the main determinant of individual susceptibility to disease including cancer [2]. The damage of DNA often caused by environmental factors such as chemicals and certain types of radiation, which, is not repaired properly would wake the stability of the genome and lead to carcinogenesis [2]. Thus, the host DNA repair systems play pivotal roles in maintaining the stability of human genome.

DNA repair ability plays an important role in maintaining genomic stability via several pathways. The base excision repair (BER), nucleotide excision repair (NER) and DNA mismatch repair are responsible for single strand DNA damages [3]; Homologous recombination (HR) and non-homologous end joining (NHEJ) repair double-strand DNA breaks (DSBs) [4].
$B R C A 1$, breast cancer 1, early onset, plays a key role in DSBs repair via HR pathway [5]. Interestingly, its involvement in other types of DNA repair has since come to light, including NER, BER, and NHEJ [5-8]. Therefore the loss or variant of $B R C A 1$ may contribute to instability of gene and tumorigenesis.

The non-synonymous P871L polymorphism in $B R C A 1$ gene lead to the amino acid substitution of leucine (Leu, L) for proline (Pro, P) at position 871, which is part of the interaction region for the recombinase RAD51, another critical protein in HR. Thus, P871L may confer cancer susceptibility. A growing number of studies have been performed to investigate its association and cancer risk; however, the conclusions are inconsistent. The discrepancies among these studies may due to the ethnic variation and relatively small sample size. To obtain a comprehensive conclusion, we conducted this metaanalysis to systematically evaluate the association between P871L and cancer risk. 
Table 1: Characteristics of studies included in this meta-analysis

\begin{tabular}{|c|c|c|c|c|c|c|c|c|c|}
\hline First author & Year & Cancer type & Ethnicity & \begin{tabular}{|l|}
$\begin{array}{l}\text { Source } \\
\text { control }\end{array}$ \\
\end{tabular} & case & control & method & HWE & Score \\
\hline Wang & 2015 & gastric & Asian & HB & 660 & 800 & PCR-RFLP & 0.204 & 9 \\
\hline Kim & 2014 & NHL & Asian & PB & 687 & 1700 & PCR-RFLP & 0.882 & 13 \\
\hline Zhang & 2013 & ESCC & Asian & $\mathrm{PB}$ & 540 & 550 & PCR-RFLP & 0.365 & 12 \\
\hline Zhang & 2013 & ESCC & Asian & PB & 588 & 600 & PCR-RFLP & 0.358 & 12 \\
\hline Chen & 2013 & NHL & Caucasian & $\mathrm{PB}$ & 459 & 532 & \begin{tabular}{|l} 
TaqMan \\
\end{tabular} & 1 & 11 \\
\hline Hasan & 2013 & breast & Caucasian & HB & 100 & 100 & TaqMan & 0.005 & 4 \\
\hline $\mathrm{Wu}$ & 2013 & breast & Caucasian & FB & 335 & 408 & \begin{tabular}{|l|} 
TaqMan \\
\end{tabular} & 0.354 & 7 \\
\hline $\mathrm{Xu}$ & 2012 & thyroid & Mixed & HB & 303 & 511 & PCR-RFLP & 0.110 & 8 \\
\hline $\mathrm{Xu}$ & 2012 & salivary gland & Caucasian & $\mathrm{HB}$ & 156 & 511 & PCR-RFLP & 0.105 & 9 \\
\hline Nicoloso & 2010 & breast & Caucasian & NR & 247 & 185 & PCR & 0.465 & 4 \\
\hline Abbas & 2010 & breast & Caucasian & PB & 3136 & 5470 & $\begin{array}{l}\text { MALDI-TOF } \\
\text { MS }\end{array}$ & 0.168 & 12 \\
\hline Wang & 2009 & breast & Asian & $\mathrm{PB}$ & 1004 & 1008 & PCR-RFLP & 0.626 & 13 \\
\hline Zhou & 2009 & cervical & Asian & $\mathrm{PB}$ & 404 & 404 & PCR-RFLP & 0.410 & 12 \\
\hline Huo & 2009 & breast & Asian & $\mathrm{PB}$ & 568 & 624 & PCR-RFLP & 0.757 & 12 \\
\hline Dombernowsky & 2009 & breast & Caucasian & $\mathrm{PB}$ & 1201 & 4119 & TaqMan & 0.187 & 10 \\
\hline Jeffrey & 2008 & Glioblastomamultiforme & Caucasian & $\mathrm{PB}$ & 112 & 112 & ParAllele & 0.010 & 9 \\
\hline Soucek & 2006 & breast & Caucasian & HB & 305 & 311 & PCR-RFLP & 0.820 & 10 \\
\hline Auranen & 2005 & ovarian & Caucasian & $\mathrm{PB}$ & 722 & 830 & TaqMan & 0.331 & 9 \\
\hline Auranen & 2005 & ovarian & Caucasian & FB & 310 & 395 & TaqMan & 0.900 & 11 \\
\hline Auranen & 2005 & ovarian & Caucasian & $\mathrm{PB}$ & 299 & 781 & \begin{tabular}{|l|} 
TaqMan \\
\end{tabular} & 0.823 & 10 \\
\hline Auranen & 2005 & ovarian & Caucasian & $\mathrm{PB}$ & 297 & 905 & \begin{tabular}{|l|} 
TaqMan \\
\end{tabular} & 0.333 & 10 \\
\hline Robert & 2005 & ovarian & Mixed & $\mathrm{PB}$ & 305 & 388 & \begin{tabular}{|l|} 
TaqMan \\
\end{tabular} & 0.141 & 11 \\
\hline Dunning & 1997 & breast & Caucasian & PB & 801 & 572 & \begin{tabular}{|l|} 
ASOs \\
hybridisation \\
\end{tabular} & 0.805 & 9 \\
\hline Dunning & 1997 & ovarian & Caucasian & PB & 223 & 572 & $\begin{array}{l}\text { ASOs } \\
\text { hybridisation }\end{array}$ & 0.805 & 7 \\
\hline
\end{tabular}

Abbreviations: HB, hospital-based; PB, population-based; CB, center-based; FB, family based; NR, no record; MAF, minor allele frequency; HWE, Hardy-Weinberg equilibrium; ESCC, esophageal squamous cell carcinoma; NHL, non-hodgkin's lymphoma

Table 2: Meta-analysis of the association between BRCA1 polymorphism and cancer risk

\begin{tabular}{|c|c|c|c|c|c|c|c|c|c|c|}
\hline \multirow{2}{*}{ Variable } & \multirow{2}{*}{$\begin{array}{l}\text { No. of } \\
\text { studies a }\end{array}$} & \multirow{2}{*}{ Sample size } & \multicolumn{2}{|l|}{ Homozygous } & \multicolumn{2}{|l|}{ Heterozygous } & \multicolumn{2}{|l|}{ Dominant } & \multicolumn{2}{|l|}{ Recessive } \\
\hline & & & OR(95\%CI) & $P_{\text {het }}^{c}$ & OR(95\%CI) & $P_{\text {het }}^{c}$ & \begin{tabular}{|l|} 
OR(95\%CI) \\
\end{tabular} & $P_{\text {het }}^{c}$ & OR(95\%CI) & $P_{\text {het }}^{c}$ \\
\hline All & 24 & $13762 / 22388$ & $0.89(0.79-1.00)$ & 0.001 & $0.99(0.93-1.06)$ & 0.054 & $0.97(0.91-1.03)$ & 0.020 & $0.89(0.80-0.99)$ & 0.003 \\
\hline \multicolumn{11}{|l|}{$\begin{array}{l}\text { Cancer } \\
\text { type }\end{array}$} \\
\hline Breast & 9 & 7697/12797 & $1.03(0.93-1.13)$ & 0.586 & \begin{tabular}{|l|}
$1.04(0.93-1.16)$ \\
\end{tabular} & 0.032 & $1.04(0.95-1.15)$ & 0.050 & $1.03(0.94-1.12)$ & \begin{tabular}{|l|l|}
0.710 \\
\end{tabular} \\
\hline Ovarian & 6 & $2156 / 3871$ & $1.00(0.84-1.19)$ & 0.715 & $1.05(0.92-1.20)$ & 0.256 & $1.04(0.92-1.18)$ & 0.294 & $0.98(0.83-1.16)$ & 0.832 \\
\hline Others $^{d}$ & 9 & $3909 / 5720$ & $0.63(0.54-0.73)$ & 0.604 & $0.90(0.82-0.99)$ & 0.617 & $0.84(0.77-0.91)$ & 0.948 & $0.66(0.57-0.77)$ & 0.273 \\
\hline \multicolumn{11}{|l|}{ Ethnicity } \\
\hline Asian & 7 & $4451 / 5686$ & $0.70(0.56-0.89)$ & 0.006 & $0.98(0.90-1.07)$ & 0.406 & $0.92(0.82-1.02)$ & 0.107 & $0.71(0.58-0.86)$ & 0.020 \\
\hline Caucasian & 15 & $8703 / 15803$ & $1.02(0.93-1.12)$ & 0.579 & $1.05(0.95-1.15)$ & 0.052 & $1.04(0.96-1.13)$ & 0.106 & $1.02(0.94-1.11)$ & 0.586 \\
\hline Mixed & 2 & \begin{tabular}{|l|}
$608 / 899$ \\
\end{tabular} & $0.80(0.62-1.04)$ & 0.936 & \begin{tabular}{|l|}
$0.77(0.63-0.94)$ \\
\end{tabular} & 0.993 & $0.81(0.70-0.94)$ & 0.924 & $0.91(0.72-1.16)$ & 0.933 \\
\hline \multicolumn{11}{|l|}{$\begin{array}{l}\text { Control } \\
\text { source }\end{array}$} \\
\hline $\mathrm{PB}$ & 16 & $11345 / 19167$ & $0.89(0.79-1.01)$ & 0.033 & $0.99(0.94-1.04)$ & 0.150 & $0.97(0.91-1.03)$ & 0.204 & $0.89(0.79-1.01)$ & 0.015 \\
\hline $\mathrm{HB}$ & 5 & $1524 / 2233$ & $0.74(0.55-1.01)$ & 0.085 & $0.90(0.78-1.03)$ & 0.478 & $0.84(0.74-0.97)$ & 0.352 & $0.79(0.59-1.06)$ & 0.071 \\
\hline \multicolumn{11}{|l|}{$\begin{array}{l}\text { Quality } \\
\text { score }\end{array}$} \\
\hline High & 19 & $12554 / 20612$ & $0.86(0.75-0.97)$ & 0.002 & $1.00(0.93-1.07)$ & 0.084 & $0.96(0.90-1.03)$ & 0.050 & $0.86(0.76-0.97)$ & 0.002 \\
\hline Low & 5 & $1208 / 1776$ & $1.06(0.79-1.43)$ & 0.160 & $0.98(0.77-1.25)$ & 0.093 & $1.01(0.78-1.30)$ & 0.039 & $1.06(0.87-1.30)$ & 0.546 \\
\hline
\end{tabular}

aThe number of studies included in our analysis.

${ }^{\mathrm{b}}$ The number of cases and controls included in the studies.

${ }^{c} P$ value of the Q-test for heterogeneity test.

'Including gastric, NHL, ESCC, cervical cancer, thyroid cancer,salivary gland carcinoma and Glioblastoma multiform. 


\section{RESULTS}

\section{Characteristics of eligible studies}

In total, 19 articles [9-27] were identified according to the inclusion and exclusion criteria, which contain 24 studies with 13762 cases and 22388 controls. The study selection process was shown in Figure 1. A total of 1559 articles were retrieved from PubMed and EMBASE. We read the title and abstract and excluded articles that are not concern about BRCA1. Then we screened out 39 articles for further evaluation. The remaining 39 articles were reviewed carefully. 20 articles were further removed, among which 10 publications not about P871L polymorphism, 5 articles without detailed data, 3 articles concerned about prognosis or survival, 1 animal study, 1 meta-analysis. Finally, 24 studies with 13762 cases and 22388 controls from 19 articles were met the inclusion and exclusion criteria in this meta-analysis. One article [11] contains two populations and another article [25] contains four populations were divided into two studies and four studies, independently. The information of these studies, including first author, year of publication, ethnicity, cancer type, number of cases and controls, HWE and quality score for each study were presented in Table 1.The distribution of genotypes in the controls of the studies was all in agreement with HWE except one study [12] due to unavailable detailed data and then only included in the dominant model.

\section{Meta-analysis results}

As shown in Table 2, significant association between P871L polymorphism and overall cancer risk was observed [homozygous model: $\mathrm{OR}=0.89,95 \% \mathrm{CI}: 0.79$ 1.00 (Figure 2); recessive model: $\mathrm{OR}=0.89,95 \% \mathrm{CI}$ : 0.80 $0.99]$. Stratified analysis by ethnicity identified significant association among Asians [homozygous model: $\mathrm{OR}=0.70$, 95\%CI: 0.56-0.89 (Figure 3); recessive model: $\mathrm{OR}=0.71$, 95\%CI: 0.58-0.86] and mixed group (dominant model: $\mathrm{OR}=0.81,95 \% \mathrm{CI}: 0.70-0.94$; heterozygous model: OR

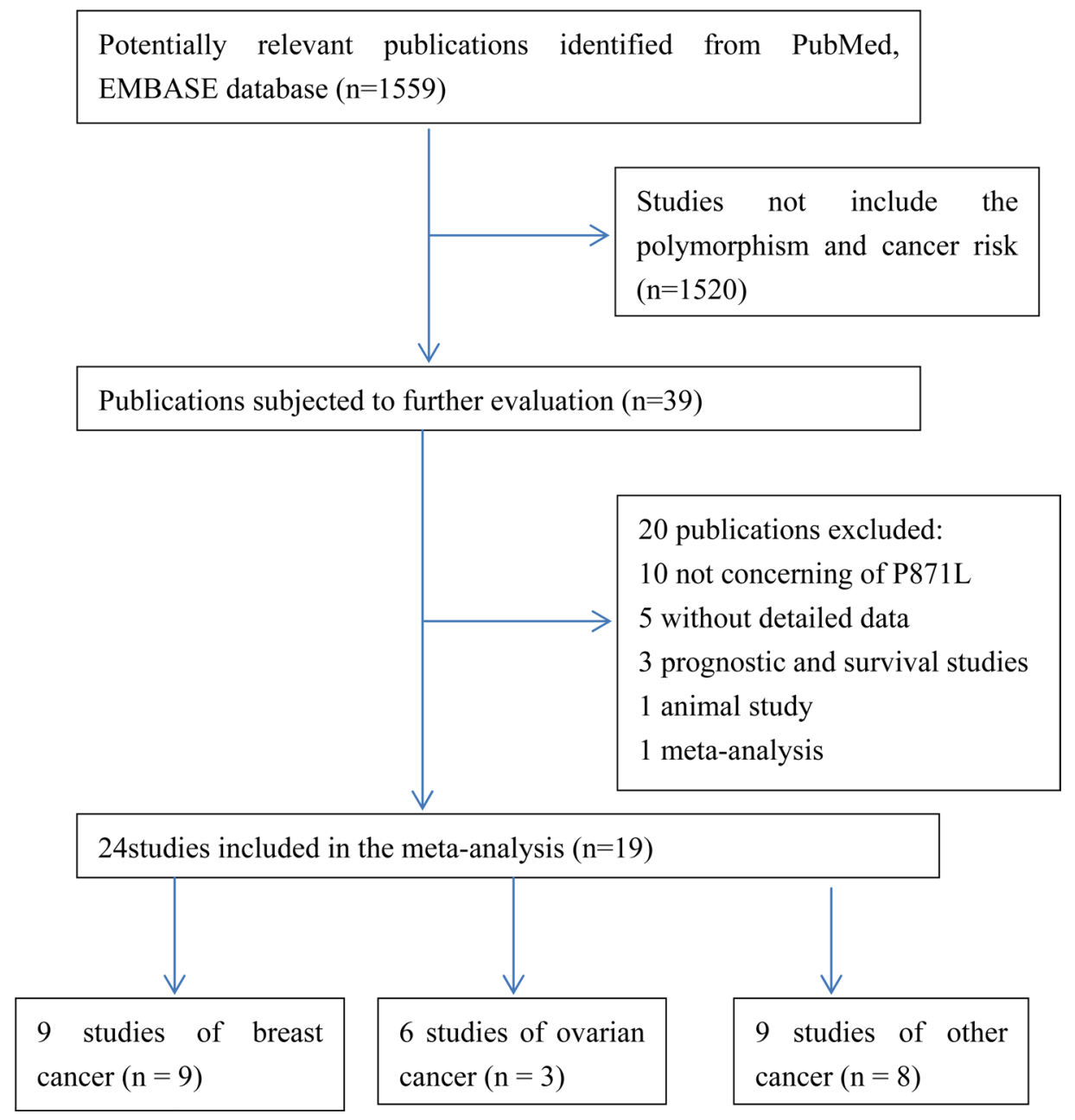

Figure 1: Flow chat of the study screening process in this meta-analysis. 
Table 3: Meta-regression analysis of the main characteristics of the 24 studies

\begin{tabular}{|c|c|c|c|c|c|c|c|c|c|c|c|c|}
\hline \multirow{2}{*}{$\begin{array}{l}\text { Study } \\
\text { characteristics }\end{array}$} & \multicolumn{3}{|c|}{ Homozygous } & \multicolumn{3}{|c|}{ Heterozygous } & \multicolumn{3}{|c|}{ Dominant } & \multicolumn{3}{|c|}{ Recessive } \\
\hline & Coef. & $95 \% \mathrm{CI}$ & $P$ & Coef. & $95 \% \mathrm{CI}$ & $P$ & Coef & $95 \% \mathrm{CI}$ & $P$ & Coef. & $95 \%$ CI & $P$ \\
\hline Cancer type & -0.23 & $-0.32,-0.14$ & $<0.001$ & -0.06 & $-0.14,-0.05$ & 0.121 & -0.10 & $-0.17,-0.03$ & 0.006 & -0.21 & $-0.30,-0.12$ & $<0.001$ \\
\hline Ethnicity & 0.16 & $-0.03,0.36$ & 0.094 & -0.05 & $-0.16,-0.08$ & 0.399 & -0.02 & $-0.13,0.10$ & 0.781 & 0.20 & $0.04,0.36$ & 0.017 \\
\hline Control source & 0.21 & $-0.02,0.44$ & 0.074 & 0.06 & $-0.09,-0.20$ & 0.444 & 0.95 & $-0.48,0.24$ & 0.182 & 0.19 & $-0.02,0.39$ & 0.075 \\
\hline Quality score & -0.22 & $-0.56,0.13$ & 0.203 & 0.03 & $-0.18,-0.24$ & 0.758 & $\begin{array}{l}-0.03 \\
\end{array}$ & $0.24,0.19$ & 0.787 & -0.23 & $-0.53,0.08$ & 0.133 \\
\hline
\end{tabular}

$=0.77,95 \%$ CI: $0.63-0.94)$. We further conducted the stratified analysis by control source and quality score of studies. As a result, a statistically significant association was observed in HB group (dominant model: $\mathrm{OR}=0.84$, 95\%CI: $0.74-0.97$ ) and the high score group (homozygous model: $\mathrm{OR}=0.86,95 \% \mathrm{CI}$ : $0.75-0.97$; 0.76-0.97; recessive model: $\mathrm{OR}=0.86,95 \% \mathrm{CI}: 0.76-0.97$ ). (Positive results were also presented in Supplemental Figure 1-8)

\section{Test of heterogeneity}

Heterogeneities exist among all investigations for P871L polymorphism and overall cancer risk (homozygous: $P_{\text {het }}=0.001$; heterozygous: $P_{\text {het }}=0.054$; dominant: $P_{\text {het }}=0.020$; recessive: $P_{\text {het }}=0.003$ ). Thus, random-effect models were chosen to calculate the pooled ORs and corresponding 95\% CIs for all genetic models. Then, a meta-regression was carried out to explore the possible source of heterogeneity by cancer type, ethnicity, control source and quality score of studies. As shown in Table 3, we found cancer type (homozygous model: $P$ $<0.001$; dominant model: $P=0.006$; recessive model: $P<0.001$ ) and ethnicity (recessive model: $P=0.017$ ) contribute to the heterogeneity in the meta-analysis, but not the control source and quality score of studies.

\section{Sensitivity analysis and publication bias}

The influence of each individual data on the combined OR was estimated by sensitivity analysis and

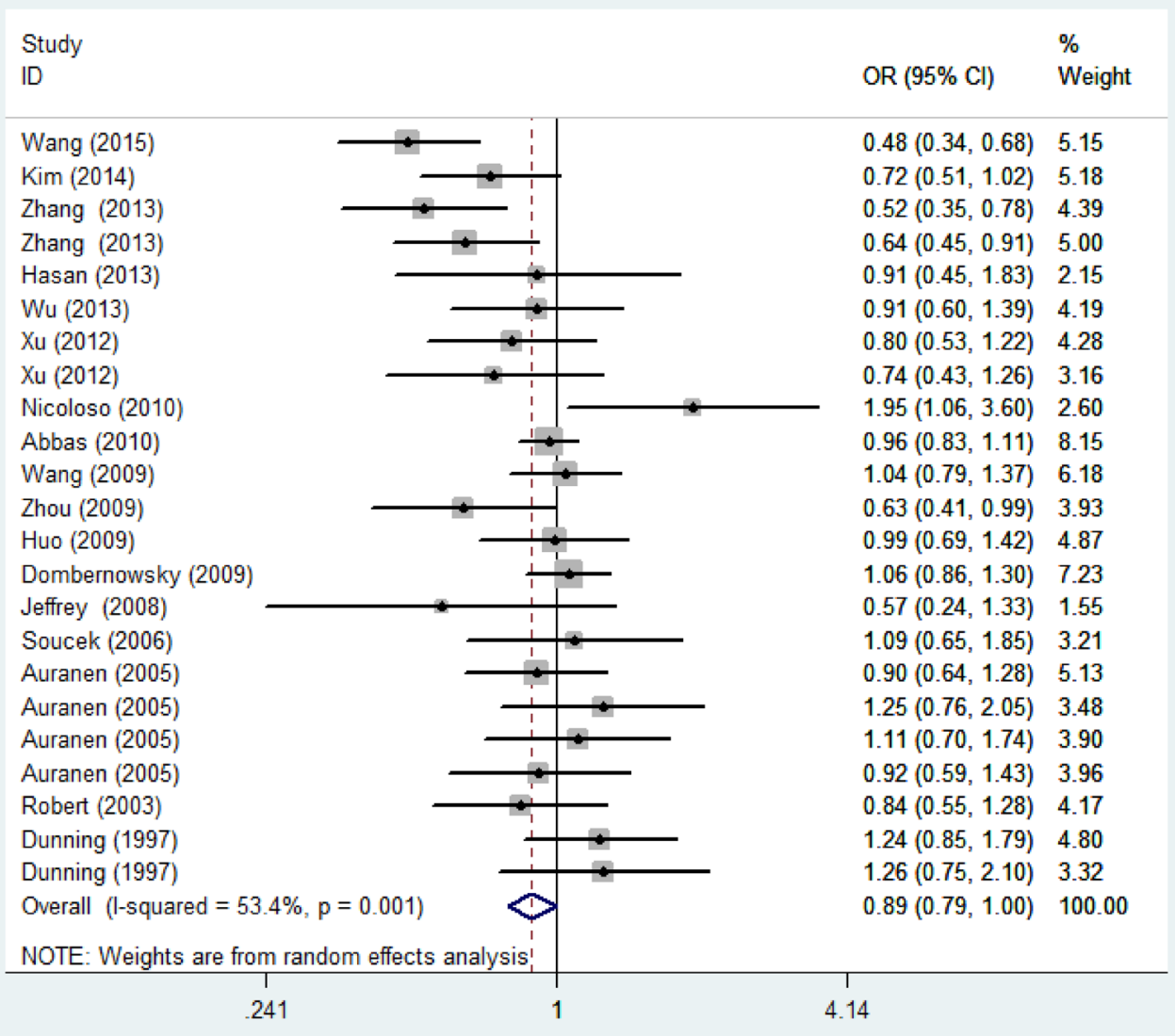

Figure 2: Forest plot of the association between rs799917 and overall cancer risk under homozygous model. For each study, the estimation of OR and its $95 \% \mathrm{CI}$ are plotted with a box and a horizontal line. $\diamond$, pooled ORs and its $95 \% \mathrm{CIs}$. 


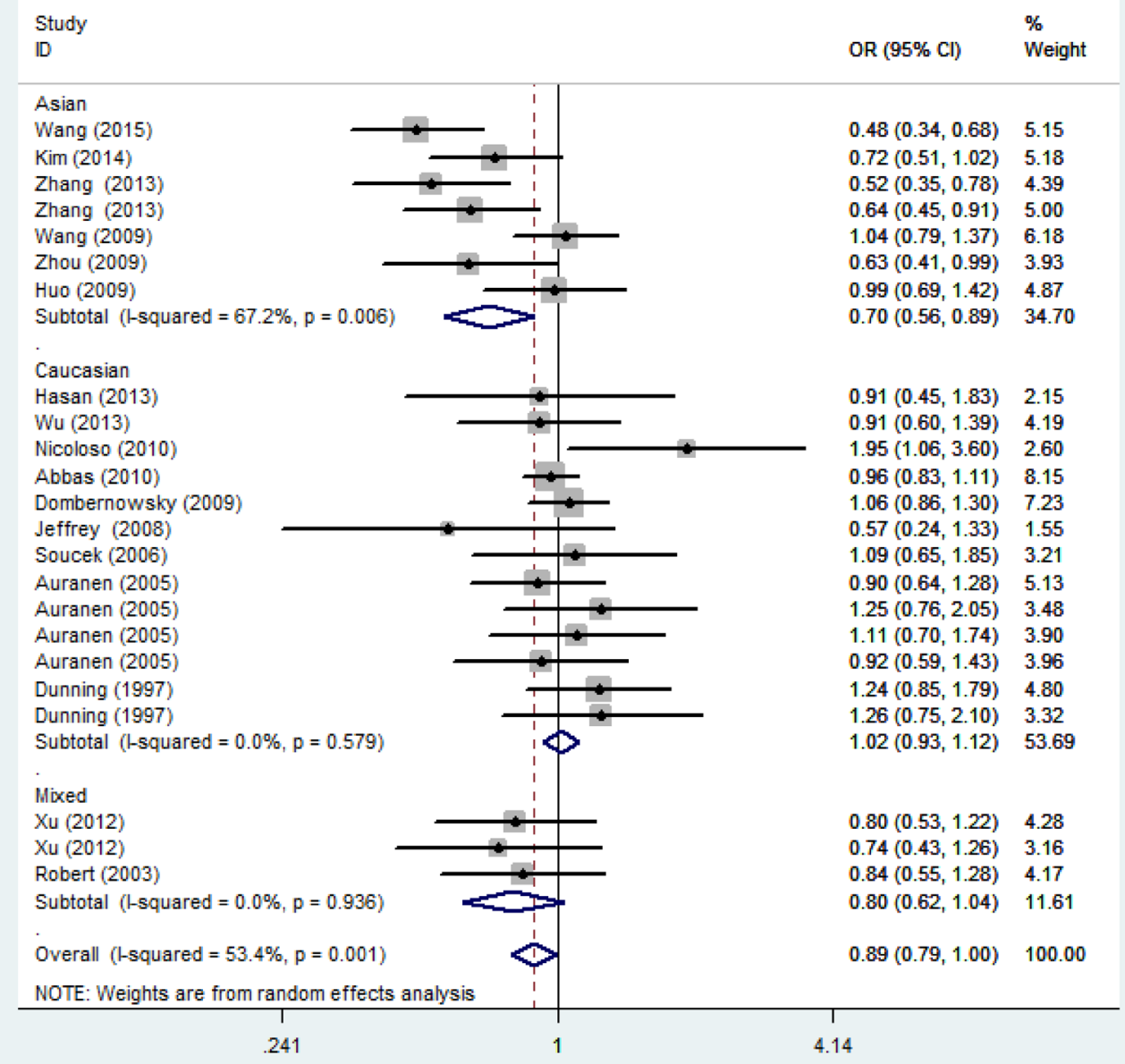

Figure 3: Forest plot of the association between rs799917 and cancer risk among ethnicity under homozygous model. For each study, the estimation of OR and its $95 \%$ CI are plotted with a box and a horizontal line. $\diamond$, pooled ORs and their $95 \%$ CIs.

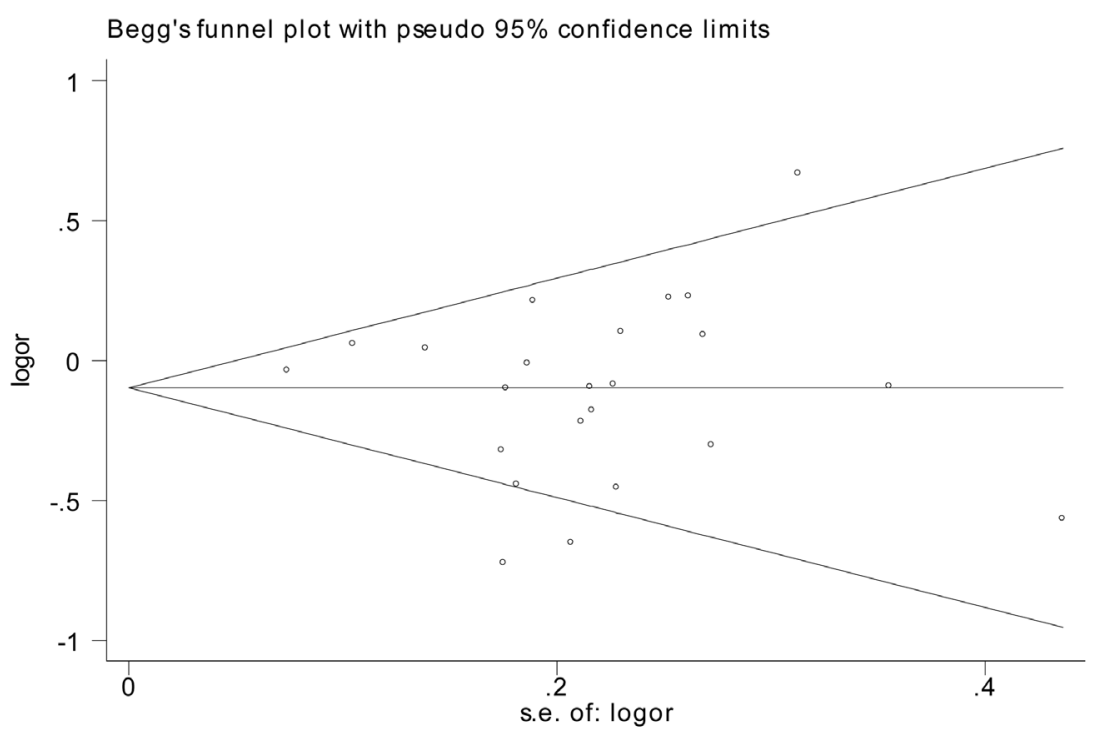

Figure 4: Funnel plot analysis to detect publication bias for rs799917 by homozygous model for overall analysis. Each point represents a separate study for the indicated association. 
no significant difference was observed in all genetic models (data were not shown). The shape of the Begg's funnel plot showed symmetric distribution in the present meta-analysis (Figure 4). The results of Egger's test were as follows: (homozygous: $P=0.543$; heterozygous: $P=$ 0.378 ; dominant: $P=0.684$; recessive: $P=0.332$ ), which further provided no evidence of publication bias.

\section{DISCUSSION}

In this study, significant association between P871L polymorphism and decreased risk of overall cancer was observed in homozygous, heterozygous and recessive model. Moreover, significant association was also found in subgroups of other cancers (a combination of gastric cancer, Non-Hodgkin lymphoma, esophageal Squamous Cell Carcinoma, cervical cancer, thyroid cancer, salivary gland carcinoma and glioblastoma multiform), Asians, mixed group, as well as high quality studies. To our knowledge, this is the first time to systematically evaluate the relevance of $B R C A 1 \mathrm{P} 871 \mathrm{~L}$ polymorphism to susceptibility of overall cancer.

The BRCA1 gene is located on chromosome17q21 and composed of 24 exons. The BRCA1 protein plays vital roles in homologous recombination [28]. Studies also support that $B R C A 1$ exerts its tumor suppression function through its involvement in cell cycle checkpoint control $[29,30]$. The P871L, a non-synonymous SNP is located in the coding region of $B R C A 1$ leads to an amino acid change from proline to leucine, is a non-conservative change as proline conveys unique structural properties to the polypeptide. However, a number of studies have reported the conflicting roles of $\mathrm{P} 871 \mathrm{~L}$ for the risk of different types of cancer. For example, P871L was indicated to be associated with risk of several cancers, such as gastric cancer, ESCC and NHL $[9,11,12]$, but not associated with cancers including thyroid carcinoma and ovarian cancer $[15,26]$. And even the same kind of cancer, the results were conflicting [18,27]. A meta-analysis conducted in 2014 including 7392 cases and 12486 controls observed no significant association between P871L and breast cancer risk [31]. Our meta-analysis with more subjects found no evidence of association between P871L and breast cancer risk either. Our work found marginal association between P871Land overall cancer risk. The discrepancy between overall cancer and stratified cancer types may due to sample size, study design, carcinogenic mechanism. In addition, relevance between P871L and overall cancer risk was found in Asians but not Caucasians in stratified analysis by ethnicity, this difference may be attributed to the different genetic background and environmental exposures.

In order to make the conclusion more credible, the publication bias analysis and sensitivity analysis was conducted. Funnel plots observed no evidence of obvious publication bias. The sensitivity analysis indicated that the results are strong and no single study yield obvious effects on the pooled ORs and the corresponding CIs.

However, several limitations in this meta-analysis should be noticed. Firstly, we could not perform further subgroup analyses for certain cancer types due to the relatively small sample size. Secondly, our results were based on unadjusted assessment of ORs, which might let our results suffer from potential confounding bias. Thirdly, even though there was no publication bias, we may miss some unpublished investigations due to studies with positive results were prone to be published. Last, the heterogeneity was existed and thus we performed the random-effects model to obtain the wider CIs, which might weaken the reliability of conclusions.

In conclusion, this comprehensive meta-analysis suggests that BRCA1 P871L polymorphism may be associated with decreased susceptibility to cancer. However, due to the limitations of the meta-analysis, welldesigned, large-scale studies will be needed to confirm these findings.

\section{MATERIALS AND METHODS}

\section{Search strategy}

We searched the PubMed and Embase databases without language limitations for all related papers using the following terms: "BRCA1 or P871L", "polymorphism or variant or variation", "cancer or carcinoma or tumor or neoplasm" (up to May 20, 2015). In addition, the references of all retrieved articles were manually searched for other related articles.

\section{Inclusion /exclusion criteria}

Every study included in the meta-analysis is accorded with following inclusion criteria: (1) casecontrol studies; (2) evaluating the association between P871L polymorphism and cancer risk; (3) and sufficient information for calculating the pooled odds ratios (ORs) with 95\% confidence intervals (CIs). Exclusion criteria: (1) review articles; (2) case reports, or case-only studies; (3) studies that estimated the risk of prognosis.

\section{Data extraction}

All data were extracted from the included studies by two authors (Miao and $\mathrm{Yu}$ ) independently. The following information was collected from each study: first author's surname, year of publication, cancer type, ethnicity, control source, sample size, genotype methods and genetic distribution of cases and controls. Cancer types were classified as breast cancer, ovarian cancer and others 
("others cancer type" group including cancer subgroups that contained less than three individual studies). All subjects were categorized as Caucasian, Asian and mixed. All eligible studies were categorized as populationbased (PB), hospital-based (HB) and family-based (FB) according to control sources. We assessed the quality of each study according to assessment criteria (Supplemental Table 1) and defined as high (quality score $\geq 9$ ) and low (quality score < 9) [32]. Disagreements were solved by full discussion until consensuses were reached.

\section{Statistical methods}

Crude ORs with the corresponding 95\% CIs were used to estimate the association between P871L polymorphism and cancer susceptibility. We used homozygous (TT vs. CC), heterozygous (CT vs. CC), dominant [(TT/CT) vs.CC] and recessive models [TT vs. $(\mathrm{CC} / \mathrm{CT})]$ as the models. The stratified analysis was performed by cancer type, ethnicity, control source and quality score of studies.

Z-test was used to determine the statistical significance of pooled ORs. Hardy-Weinberg equilibrium (HWE) was examined by Chi-square test based on the genotype distribution among controls. Heterogeneity was analyzed using the Chi-square based Q-test. When no heterogeneity exist $(P>0.10$ for the Q-test), the fixed effect model was performed to estimate the combined OR [33]. Otherwise, a random effect model was used to calculate the pooled OR [34]. In addition, the heterogeneity was quantified by the $I^{2}$ statistics and a larger $I^{2}$ value indicating a greater heterogeneity [35]. Sensitivity analysis that used to evaluate the effect of data from each study on pooled ORs was performed by sequential deleting a single study each time. Publication bias among the literatures was evaluated by Begg's funnel plot and Egger's test [36]. STATA 11.0 software (Stata Corporation, College Station, TX) was used to perform all statistical tests, all the $P$ values were two-sided test and $P<0.05$ was considered statistically significant.

\section{ACKNOWLEDGMENTS AND FUNDING}

This work was supported in part by National Natural Science Foundation of China (81672678), Priority Academic Program Development of Jiangsu Higher Education Institutions (PAPD, 2014-37), Specialized Research Fund for the Doctoral Program of Higher Education of China (20133234120013), and The Project of Invigorating Health Care through Science, Technology and Education (Jiangsu Provincial Medical Youth Talent).

\section{CONFLICTS OF INTEREST}

The authors have declared that no competing interest

\section{REFERENCES}

1. Torre LA, Bray F, Siegel RL, Ferlay J, Lortet-Tieulent J, Jemal A. Global cancer statistics, 2012. CA Cancer J Clin. 2015; 65:87-108.

2. Institute of Medicine Roundtable on Environmental Health Sciences R. Medicine. In: Wilson S, Jones L, Couseens C, Hanna K, editors. Cancer and the Environment: GeneEnviromentInteraction. (Washington (DC): National Academies Press. US; 2002.

3. Christmann M, Tomicic MT, Roos WP, Kaina B. Mechanisms of human DNA repair: an update. Toxicology. 2003; 193:3-34.

4. Pierce AJ, Stark JM, Araujo FD, Moynahan ME, Berwick M, Jasin M. Double-strand breaks and tumorigenesis. Trends Cell Biol. 2001; 11:S52-59.

5. Zhang J, Powell SN. The role of the BRCA1 tumor suppressor in DNA double-strand break repair. Mol Cancer Res. 2005; 3:531-39.

6. Alli E, Sharma VB, Hartman AR, Lin PS, McPherson L, Ford JM. Enhanced sensitivity to cisplatin and gemcitabine in Brca1-deficient murine mammary epithelial cells. BMC Pharmacol. 2011; 11:7.

7. Hastak K, Alli E, Ford JM. Synergistic chemosensitivity of triple-negative breast cancer cell lines to poly(ADP-Ribose) polymerase inhibition, gemcitabine, and cisplatin. Cancer Res. 2010; 70:7970-80.

8. Hartman AR, Ford JM. BRCA1 induces DNA damage recognition factors and enhances nucleotide excision repair. Nat Genet. 2002; 32:180-84.

9. Wang K, Xu L, Pan L, Xu K, Li G. The functional BRCA1 rs799917 genetic polymorphism is associated with gastric cancer risk in a Chinese Han population. Tumour Biol. 2015; 36:393-97.

10. Kim HN, Kim NY, Yu L, Kim YK, Lee IK, Yang DH, Lee JJ, Shin MH, Park KS, Choi JS, Kim HJ. Polymorphisms in DNA repair genes and MDR1 and the risk for non-Hodgkin lymphoma. Int J Mol Sci. 2014; 15:6703-16.

11. Zhang X, Wei J, Zhou L, Zhou C, Shi J, Yuan Q, Yang $\mathrm{M}$, Lin D. A functional BRCA1 coding sequence genetic variant contributes to risk of esophageal squamous cell carcinoma. Carcinogenesis. 2013; 34:2309-13.

12. Chen Y, Zheng T, Lan Q, Kim C, Qin Q, Foss F, Chen X, Holford T, Leaderer B, Boyle P, Wang C, Dai M, Liu Z, et al. Polymorphisms in DNA repair pathway genes, body mass index, and risk of non-Hodgkin lymphoma. Am J Hematol. 2013; 88:606-11.

13. Hasan TN, Shafi G, Syed NA, Alsaif MA, Alsaif AA, Alshatwi AA. Lack of association of BRCA1 and BRCA2 variants with breast cancer in an ethnic population of Saudi Arabia, an emerging high-risk area. Asian Pac J Cancer Prev. 2013; 14:5671-74.

14. Wu HC, Delgado-Cruzata L, Machella N, Wang Q, Santella RM, Terry MB. DNA double-strand break repair genotype exists. 
and phenotype and breast cancer risk within sisters from the New York site of the Breast Cancer Family Registry (BCFR). Cancer Causes Control. 2013; 24:2157-68.

15. Xu L, Doan PC, Wei Q, Liu Y, Li G, Sturgis EM. Association of BRCA1 functional single nucleotide polymorphisms with risk of differentiated thyroid carcinoma. Thyroid. 2012; 22:35-43.

16. Xu L, Doan PC, Wei Q, Li G, Sturgis EM. Functional single-nucleotide polymorphisms in the BRCA1 gene and risk of salivary gland carcinoma. Oral Oncol. 2012; 48:84247.

17. Nicoloso MS, Sun H, Spizzo R, Kim H, Wickramasinghe P, Shimizu M, Wojcik SE, Ferdin J, Kunej T, Xiao L, Manoukian S, Secreto G, Ravagnani F, et al. Singlenucleotide polymorphisms inside microRNA target sites influence tumor susceptibility. Cancer Res. 2010; 70:278998.

18. MARIE-GENICA Consortium on Genetic Susceptibility for Menopausal Hormone Therapy Related Breast Cancer Risk. Polymorphisms in the BRCA1 and ABCB1 genes modulate menopausal hormone therapy associated breast cancer risk in postmenopausal women. Breast Cancer Res Treat. 2010; 120:727-36.

19. Wang Z, Xu Y, Tang J, Ma H, Qin J, Lu C, Wang X, Hu Z, Wang X, Shen H. A polymorphism in Werner syndrome gene is associated with breast cancer susceptibility in Chinese women. Breast Cancer Res Treat. 2009; 118:16975.

20. Zhou X, Han S, Wang S, Chen X, Dong J, Shi X, Xia Y, Wang X, Hu Z, Shen H. Polymorphisms in HPV E6/ E7 protein interacted genes and risk of cervical cancer in Chinese women: a case-control analysis. Gynecol Oncol. 2009; 114:327-31.

21. Huo X, Lu C, Huang X, Hu Z, Jin G, Ma H, Wang X, Qin J, Wang X, Shen H, Tang J. Polymorphisms in BRCA1, BRCA1-interacting genes and susceptibility of breast cancer in Chinese women. J Cancer Res Clin Oncol. 2009; 135:1569-75.

22. Dombernowsky SL, Weischer M, Freiberg JJ, Bojesen SE, Tybjaerg-Hansen A, Nordestgaard BG. Missense polymorphisms in BRCA1 and BRCA2 and risk of breast and ovarian cancer. Cancer Epidemiol Biomarkers Prev. 2009; 18:2339-42.

23. Chang JS, Yeh RF, Wiencke JK, Wiemels JL, Smirnov I, Pico AR, Tihan T, Patoka J, Miike R, Sison JD, Rice T, Wrensch MR. Pathway analysis of single-nucleotide polymorphisms potentially associated with glioblastoma multiforme susceptibility using random forests. Cancer Epidemiol Biomarkers Prev. 2008; 17:1368-73.
24. Soucek P, Borovanova T, Pohlreich P, Kleibl Z, Novotny J. Role of single nucleotide polymorphisms and haplotypes in BRCA1 in breast cancer: czech case-control study. Breast Cancer Res Treat. 2007; 103:219-24.

25. Auranen A, Song H, Waterfall C, Dicioccio RA, Kuschel B, Kjaer SK, Hogdall E, Hogdall C, Stratton J, Whittemore AS, Easton DF, Ponder BA, Novik KL, et al. Polymorphisms in DNA repair genes and epithelial ovarian cancer risk. Int J Cancer. 2005; 117:611-18.

26. Wenham RM, Schildkraut JM, McLean K, Calingaert B, Bentley RC, Marks J, Berchuck A. Polymorphisms in BRCA1 and BRCA2 and risk of epithelial ovarian cancer. Clin Cancer Res. 2003; 9:4396-403.

27. Dunning AM, Chiano M, Smith NR, Dearden J, Gore M, Oakes S, Wilson C, Stratton M, Peto J, Easton D, Clayton D, Ponder BA. Common BRCA1 variants and susceptibility to breast and ovarian cancer in the general population. Hum Mol Genet. 1997; 6:285-89.

28. Moynahan ME, Cui TY, Jasin M. Homology-directed dna repair, mitomycin-c resistance, and chromosome stability is restored with correction of a Brcal mutation. Cancer Res. 2001; 61:4842-50.

29. Roy R, Chun J, Powell SN. BRCA1 and BRCA2: different roles in a common pathway of genome protection. Nat Rev Cancer. 2011; 12:68-78.

30. Huen MS, Sy SM, Chen J. BRCA1 and its toolbox for the maintenance of genome integrity. Nat Rev Mol Cell Biol. 2010; 11:138-48.

31. Qin TT, Chen T, Zhang Q, Du HN, Shu YQ, Luo K, Zhu LJ. Association between BRCA1 rs799917polymorphism and breast cancer risk: A meta-analysis of 19,878 subjects. Biomedicine \&pharmacotherapy. 2014; 68:905-910.

32. da Silva SD, Ferlito A, Takes RP, Brakenhoff RH, Valentin MD, Woolgar JA, Bradford CR, Rodrigo JP, Rinaldo A, Hier MP, Kowalski LP. Advances and applications of oral cancer basic research. Oral Oncol. 2011; 47:783-91.

33. Mantel N, Haenszel W. Statistical aspects of the analysis of data from retrospective studies of disease. J Natl Cancer Inst. 1959; 22:719-48.

34. DerSimonian R, Laird N. Meta-analysis in clinical trials. Control Clin Trials. 1986; 7:177-88.

35. Higgins JP, Thompson SG. Quantifying heterogeneity in a meta-analysis. Stat Med. 2002; 21:1539-58.

36. Whitehead A, Whitehead J. A general parametric approach to the meta-analysis of randomized clinical trials. Stat Med. 1991; 10:1665-77. 